\title{
Urdimento
}

Revista de Estudos em Artes Cênicas

E-ISSN: 2358.6958

\section{Para corroer a cisnormatividade carcerária: o projeto Artetransformando: LGBTQI+ Encarceradxs}

Sergio Costa Junior

Vicentina Flôr

\section{Para citar este artigo:}

COSTA JUNIOR, Sergio; FLÔR, Vicentina. Para corroer a cisnormatividade carcerária: 0 projeto Artetransformando: LGBTQI+ Encarceradxs. Urdimento, Florianópolis, v. 3, n. 39, nov./dez. 2020.

DOI: http:/dx.doi.org/10.5965/14145731033920200116

Este artigo passou pelo Plagiarism Detection Software | iThenticate 


\title{
Para corroer a cisnormatividade carcerária: \\ o projeto Artetransformando: LGBTQI+ Encarceradxs
}

Sergio Costa Junior ${ }^{1}$

Vicentina Flôr ${ }^{2}$

\begin{abstract}
Resumo
O presente artigo apresenta um relato sobre o convívio criativo na Penitenciária Evaristo de Moraes, no Rio de Janeiro, com um grupo de pessoas dissidentes sexuais e desobediente de gênero. Com destaque às vivências trans no cárcere, esse texto expõe as táticas de contrabando - do cultivo da beleza, sensibilidade e arte - que visam problematizar a instituição penal como um território de radicalização da violência cisnormativa.
\end{abstract}

Palavras-chave: Gênero. Prisão. Cisnormatividade. Teatro. Transgêneros.

\section{To Corrode Prison Cisnormativity: \\ the Artetransformando: LGBTQI+ Encarceradxs project}

\begin{abstract}
This article presents a report of the creative living together at the Evaristo de Moraes Penitentiary, in Rio de Janeiro, with a group of sexual dissident and disobedient people. With emphasis on trans experiences in prison, this text exposes the smuggling tactics - since the cultivation of beauty, sensitivity and art - that aim to problematize the penal institution as a territory of radicalization of cisnormative violence.
\end{abstract}

Keywords: Gender. Prison. Cisnormativity. Drama. Transgenders.

\footnotetext{
${ }^{1}$ Também conhecido como Sergio Kauffmann, é Ator, músico, palhaço e professor. Formado pela CAL- Casa de Artes de Laranjeiras e em Licenciatura em Artes Cênicas pela UNIRIO. Mestrando no Programa de PósGraduação em Artes Cênicas da UNIRIO (Bolsista MSC- 10/FAPERJ), onde desenvolve a pesquisa intitulada Tráfico-Teatro: Percurso de Desobediência à Cisnormatividade Carcerária, com orientação da Profa. Dra. Marina Henriques Coutinho. É integrante do Programa de Extensão Cultura na Prisão. skauffmanncosta@gmail.com

2 Atriz, graduanda em Ensino do Teatro pela Unirio e pesquisadora no projeto ArteTransformando: LGBTIQ+ encarceradxs do Programa Cultura na Prisão. flor.vhbernardes@gmail.com
} 


\title{
Para Corroer la Cisnormatividad de la Prisión: \\ el proyecto Artetransformando: LGBTQI+ Encarceradxs
}

\begin{abstract}
Resumen
Este artículo presenta un relato de la convivencia creativa en la Penitenciaría Evaristo de Moraes, en Río de Janeiro, con un grupo de disidentes sexuales y desobedientes de género. Con énfasis en las experiencias trans en la prisión, este texto expone las tácticas de contrabando - desde el cultivo de la belleza, sensibilidad y el arte - que apuntan a problematizar la institución penal como territorio de la radicalización de la violencia cisnormativa.
\end{abstract}

Palabras clave: Género. Prisión. Cisnormatividad. Teatro. Transgéneros. 
No contexto do cárcere, ora como em toda a extensão da sociedade, existe uma estrutura cisheteronormativa que não converge com o direito ao respeito das identidades de gênero e sexualidades. É mais provável que uma pessoa trans conheça ou compreenda a realidade cisgênero do que o contrário.

Visto que, ao nascermos, nossa identidade é constituída a partir do sexo biológico, fora desta dicotomia entre mulher/vagina $\times$ homem/pênis existe a resistência de quem não obedece a tais normas de gênero. Este reflexo social aponta para a desvalorização e repressão das subjetividades trans, pois se nega a compreender que somos todos/as diferentes, individualizados/as e particulares, e também a enxergar que enquanto buscamos conhecer nosso próximo podemos ter a oportunidade de reconhecer outros aspectos de nós mesmos/as. Como cita Jaqueline Gomes de Jesus,

toda mudança em favor da justiça e da igualdade começa quando entendemos melhor quem são as outras pessoas, e o que elas vivem, superando mitos e medos. Sem respeito à identidade de cada um/a, não garantimos a cidadania das pessoas e silenciosamente calamos sonhos, esperanças, aumentamos os desafios que as pessoas têm de enfrentar na vida. Cada ser humano tem múltiplas formas de vivenciar sua identidade, e isso não muda para as pessoas transgênero: não são todas iguais. A identidade de gênero não esgota a subjetividade de uma pessoa, nem sua subjetividade se restringe ao fato de ser transexual. (Jesus, 2012, p. 32).

Transpondo esse pensamento para a nosso trabalho, costumamos refletir diante de atitudes transfóbicas e racistas: estas manifestações de pré-concepção de gênero ou raça invisibilizam as identidades trans ao mesmo tempo que evocam o projeto de centricidade da identidade cisgênera que está nos pilares não só das relações como nas instituições totais (Goffman, 1974) do C/Stema, provocando a perpetuação das "normas de comportamento que nunca antes foram nomeadas" (Mombaça, 2016, p. 10). O termo ClStema não é equivocado. Estamos falando do sistema de normas que favorece pessoas cisgênero em detrimento das pessoas trans e não-binárias.

Através disso a proposta aqui é expor e analisar os fatores sociais e culturais que estão impregnados no C/Stema carcerário e sua corrosão a partir das brechas 
de resistência, que provocam a deterioração dos regimes normatizados ao reivindicar e inserir a participação das identidades dissidente sexuais ou desobediente de gênero através de demandas específicas.

Por outro lado, também acompanhamos movimentos de fuga dessas identidades contra a perseguição contínua do C/Stema. O comportamento geral, a montação, o corte, a mutilação, a dualidade, a hormonização e o desejo de ser plenamente reconhecida como mulher foram percebidas e trabalhadas nas esferas da estética teatral através do projeto de extensão e pesquisa Artetransformando: LGBTQI+ encarceradxs, vinculado ao Programa de Extensão Cultura na Prisão, ambos da UNIRIO ${ }^{3}$. Porém tais discussões não cessam no palco. Esses temas que atravessam a vida de cada mulher que afeta e é afetada durante esse processo se perpetuam para além da própria vivência, tornando outras identidades dissidente sexuais ou desobedientes de gênero possíveis e vivas, para muito além do cárcere.

\section{Dissidências sexuais e desobediências de gênero ${ }^{4}$ no cárcere}

Em janeiro de 2020 o governo federal lançou o primeiro documento oficial com um diagnóstico nacional do tratamento penal às pessoas dissidentes sexuais e desobedientes de gênero. ${ }^{5}$ Apesar de uma importante contribuição para a compreensão do impacto do cárcere nessa população, os procedimentos utilizados apontam algumas problemáticas. A primeira etapa da pesquisa foi desenvolvida através de formulários direcionados às $1.449^{6}$ unidades prisionais do

${ }^{3}$ Criado em 1997, é coordenado pelas professoras Natália Fiche e Viviane Narvaes. O programa desenvolve diversas ações em prisões e oferece aos/às estudantes da Escola de Teatro da UNIRIO uma experiência formativa sobre teatro e encarceramento. No programa, os/as discentes são divididos/as em equipes e facilitam oficinas de teatro em instituições penais do Rio de Janeiro. Saiba mais em: http://www.unirio.br/cla/escoladeteatro/extensao/programa-cultura-na-prisao Acesso em: 05/12/2020.

${ }^{4}$ Utilizaremos esses termos a fim de evitar a sigla LGBTQI+ e suas possíveis atualizações. Nos apoiamos na crítica realizada por Leal (2018), que identifica a sigla como "um marcador de sexualidade cisnormativo" que tende a limitar a experiência sexual de pessoas trans e contribui para confusões entre gênero e sexualidade.

${ }^{5}$ Relatório lançado pelo Ministério da Mulher, Família e dos Direitos Humanos, intitulado LGBT nas prisões do Brasil: Diagnóstico dos procedimentos institucionais e experiências de encarceramento.

${ }^{6}$ Segundo o último levantamento nacional do Departamento de Administração Penitenciária Nacional (DEPEN), 
país, mas somente 39\% dessas unidades participaram da pesquisa. Depois, nas visitas in loco, momento em que se atesta as condições das prisões através do relato das pessoas encarceradas, somente uma penitenciária de cada estado recebeu o comitê de análise e entrevistas.

O estudo mapeia o número de celas e alas especiais dedicadas a esse grupo, o perfil dos/das encarcerados/as, os crimes cometidos e violações de direitos recorrentes. O documento aponta que a maioria das travestis foram encarceradas por tráfico ou roubo e possuem de 18 a 24 anos. O estudo também indica que há 618 travestis encarceradas em todo Brasil, dado que deve ser questionado considerando as limitações dos procedimentos de coleta de dados.

Infelizmente, devido à natureza dos dados e a dificuldade de garantir a homogeneidade da amostra e a padronização do procedimento de coleta de dados, os dados quantitativos de pessoas LGBT nas prisões do Brasil não pode ser utilizado como instrumento de censo. Não há como garantir que todas as pessoas LGBT nas unidades prisionais respondentes foram efetivamente consultadas. Tampouco é possível dizer que os LGBT que, de fato, foram consultados, gozavam de ampla liberdade para declarar sua sexualidade e sua identidade de gênero sem risco de sanções tanto administrativas, quanto por parte dos outros internos. (LGBT nas Prisões, 2020, p. 20).

Tal como exposto em Kauffmann (2019, p.109), nos últimos anos, esse tipo de pesquisa esteve a cargo de instituições privadas, que financiaram projetos como o Passagens - Rede de Apoio a LGBTs nas Prisões', organizado pela ONG Somos, de Porto Alegre, onde foi possível mapear a condição de prisões no Rio Grande do Sul, Minas Gerais, Mato Grosso, São Paulo e Ceará.

A comunidade dissidente sexual e desobediente de gênero é extremamente vulnerável e está na parte mais baixa da pirâmide da hierarquia do cárcere, sofrendo violências inimagináveis. Quando se trata de pessoas trans, fica ainda mais evidente como são afetadas pela seletividade penal que compõe o sistema carcerário brasileiro. Basta fazer referência a Jesus (2014), para lembrarmos que o

em junho de 2017, o Brasil possui 1507 estabelecimentos penais.

${ }^{7}$ Financiamento realizado pela organização privada brasileira chamada Fundo Brasil de Direitos Humanos. 
sistema penal usa critérios bem específicos para o encarceramento, alimentando um projeto de aprisionamento do grupo denominado como PPP (preto, pobre e puta).

Em uma mobilização inédita na Câmara dos Deputados, a deputada Fernanda Melchionna (PSOL-RS), convocou uma audiência pública ${ }^{8}$ para discutir a situação de pessoas dissidentes sexuais e desobedientes de gênero nas prisões brasileiras.

A audiência pública levantou as questões-chave sobre a condição dessa população em nível nacional. Na maior parte dos relatos, foi destacada a diferença no tratamento em relação ao resto da massa carcerária, com evidência ao acesso restrito aos programas de saúde e educação. Foi destacada uma relação extensa de violações de direitos, como: abusos sexuais, restrições às visitas e impedimento da manutenção de elementos da identidade (cabelos, roupas e acessórios femininos, por exemplo). Em relação a essa última demanda, destaca-se a necessidade da retificação da utilização do nome social, o que na maioria das vezes não é feito, com o intuito claro de constranger e violentar. Outra reivindicação comum é a falta de suporte jurídico, psicológico, e a necessidade de apoio para a hormonização e realização de exames.

Em outubro de 2020, o Conselho Nacional de Justiça (CNJ) estabeleceu ato normativo ${ }^{9}$ sobre diretrizes que devem ser adotadas para pessoas dissidentes sexuais e desobedientes de gênero em privação de liberdade. A decisão é um importante avanço pois possibilita a autodeclaração de gênero e sexualidade em juízo e, no caso de pessoas trans, poderão ser alocadas em penitenciárias masculinas ou femininas, com ala ou celas específicas, de acordo com suas escolhas. A decisão também aponta que as pessoas trans terão direito ao uso do nome social e poderão solicitar retificação no registro civil.

\footnotetext{
${ }^{8}$ Requerimento 224/2019

9 Saiba mais em: https://atos.cnj.jus.br/files/original172444202010155f8885dcb6722.pdf Acesso em: 05 dez. 2020.
} 


\section{Evaristo de Moraes}

A penitenciária masculina Evaristo de Moraes, em São Cristóvão, região central do Rio de Janeiro, ocupa um galpão que foi utilizado como garagem de ônibus e readaptado para ser utilizado como unidade prisional. Esse dado já nos indica a precariedade do espaço (Kauffmann, 2019).

O único relatório encontrado que expõe a condição das pessoas trans nessa penitenciária até o momento é o Mulheres, Meninas e Privação de Liberdade, organizado pelo Mecanismo Estadual de Prevenção e Combate à Tortura do Rio de Janeiro (MECPT/RJ) em 2015. Seu texto destaca narrativas de tortura e violência às presas encontradas com entorpecentes e atos de violência cometidos pelo Serviço de Operações Especiais (SOE), responsável pelo transporte dos/as presos/as para outros espaços. Além disso, relata que as presas estão expostas a uma dupla disciplina: "aquela feita pelos agentes, que devem ser obedecidas por todos, e as feitas pelos outros presos homens, as quais elas se veem obrigadas a se submeter". Essa estrutura, em diversas prisões, acaba as conduzindo a relações sexuais forçadas e outras formas de agressão não reveladas. ${ }^{10}$ Ao mesmo tempo, o documento também observa que a instituição preserva um ambiente de mínimo acolhimento e respeito,

apesar da existência de problemas relacionados à saúde, bem como à revista e visita íntimas. Isso porque as travestis e transexuais alocadas naquele presídio têm permissão, por exclusiva discricionariedade do gestor, para manter os cabelos longos, utilizar vestuário feminino, receber objetos pessoais de uso feminino e costumam ser tratadas pelo nome social. (MECPT/RJ, 2015, p.53).

Apesar desses dados, não são poucos os relatos de agentes que se negam a respeitar os direitos básicos, ferindo a orientação dada pela Resolução 558, de 2015, da Secretaria de Administração Penitenciária do Estado do Rio de Janeiro

10 Informação de outro relatório, produzido pelo Núcleo de Defesa da Diversidade Sexual e Direitos Homoafetivos (NUDIVERSIS) da Defensoria Pública do estado do Rio de Janeiro. Foi realizado antes da Resolução 558, e, portanto, expõem um quadro ainda mais grave sobre a população dissidente sexual e desobediente de gênero encarcerada no Rio de Janeiro. 
(SEAP/RJ), onde está exposto a obrigatoriedade em permitir a livre expressão e identidade de gênero dentro das unidades.

\section{Percurso corrosivo}

As oficinas teatrais foram conduzidas de dezembro de 2018 a dezembro de 2019. Além dos/os autores/as desse artigo, compuseram a equipe os/as estudantes Osni Silva e Natali Barbosa, também integrantes do Programa de Extensão Cultura na Prisão.

Tivemos cerca de 40 encontros, sempre às sextas-feiras pela manhã, no horário de $9 \mathrm{~h}$ às 12h. Apesar disso, nem sempre trabalhamos durante todas essas horas e, em alguns dias, a depender do processo de autorização para a entrada, trabalhávamos apenas 30 minutos.

A partir das referências apreendidas na disciplina Por uma pragmática da suficiência: deslocamentos entre a pesquisa, a matéria e a escrita, conduzida por Luiza Leite ${ }^{11}$, na UFRJ, construímos um registro sensível semanal através de textos, imagens e cenas.

Quarenta e cinco alunas passaram por nossas atividades ao longo do último ano. Todas elas são travestis. Tínhamos, por semana, uma lista com 20 inscritas, mas raramente conseguíamos que todas estivessem presentes. Fizemos debates importantes sobre a condição delas na penitenciária e sobre suas vivências, o que contribuiu para a apresentação de perspectivas muito diversas sobre identidade de gênero, expressão de gênero e sexualidade.

Faremos o relato do trabalho a partir dos títulos dos exercícios que orientaram as criações e as discussões centrais do processo: constelação de desejos; objetos femininos; quem sou eu no salão; hoje vou ao salão de beleza porque amanhã é

${ }^{11}$ Professora e pós-doutoranda no Programa de Pós-graduação em Artes da Cena, da UFRJ. Graduada em Comunicação Social (jornalismo) pela Pontifícia Universidade Católica do Rio de Janeiro (1998), com mestrado em antropologia pelo Programa de Pós-Graduação em Antropologia Social do Museu Nacional/ UFRJ (2003) e doutorado em Literatura Comparada pelo Programa de Pós-Graduação em Letras da UERJ (2012), tem experiência na área de antropologia e literatura, com ênfase em estudos sobre narrativas ameríndias, tradução intersemiótica, regimes da visualidade, relação entre imagem e texto e educação visual. 
um dia importante; o que está por trás da foto?; como montar uma travesti? e meu nome social.

Todos os textos criados pelas integrantes e apresentados nesse artigo são transcrições dos documentos originais e não sofreram revisão ortográfica. No corpo do texto, portanto, optamos por dispensar a utilização do [S/C]. Os materiais estarão propositalmente sem autoria já que não conseguimos reencontrá-las para que pudessem ler e opinar sobre suas criações e autorizar a publicação com identificação. Esse desencontro é recorrente e ocorre por diversos fatores, como: transferências repentinas; punições; mudanças de ala ou, nos melhores casos, LIBERDADE!

\section{Constelação de desejos}

Na primeira fase do trabalho, tínhamos uma alta rotatividade de alunas e turmas bastante cheias. A divulgação de que iniciaríamos uma atividade dedicada às pessoas trans mobilizou grande parte da comunidade dissidente sexual e desobediente de gênero e, assim, tivemos uma lista com mais nomes do que achávamos que seria possível para nossas aulas.

As primeiras aulas ocorreram na quadra de esportes, nos fundos da cadeia, em uma espécie de espaço de transição entre a "prisão comum" e a "prisão evangélica". 12 Aos poucos, conseguimos compreender o envolvimento já existente das primeiras participantes com as artes. Algumas delas compartilharam suas experiências como atrizes, na capoeira, como cantoras e instrumentistas. Anunciamos - quase como uma resposta imediata a essas narrativas - que poderíamos desenvolver um trabalho que resgatasse essas experiências, organizando um grande sarau, onde elas poderiam "arrasar, né?". Foi assim que uma das participantes reagiu a essa primeira proposta, ao mesmo tempo em que

\footnotetext{
${ }^{12}$ Esta divisão específica denúncia o forte papel interventivo das religiões neopentecostais no estado, uma vez que oferece uma organização e estrutura própria, com ambientes mais limpos e outros benefícios. No entanto, os requisitos para a utilização desse espaço afetam diretamente as vivências trans, pois as lideranças religiosas impõem regras violentas que obrigam as mulheres a abdicarem do uso de roupas femininas e dos seus nomes sociais; ou seja, elas se veem obrigadas a adotar estratégias de proteção e assumem uma passabilidade cis.
} 
ouvíamos risadas, batidas de palmas e vozes animadas.

Mas essa empolgação foi imediatamente acompanhada pela percepção das nossas previsíveis impossibilidades. Cabe a nós a honestidade em falar sobre as condições que possuímos para o desenvolvimento do trabalho e o cuidado para não prometer o que não poderemos cumprir.

Uma das alunas anunciou que tocava saxofone e flauta, e fez um relato emocionado sobre a saudade que sentia da música. Perguntou se poderíamos trazer esses instrumentos para que pudesse treinar na sua cela. Com a mesma espontaneidade com que fez esse comentário, interrompeu o pedido, esquecendo a quantidade de pessoas que convivem com ela no espaço apertado para cerca de 150 pessoas. Por poucos segundos, esqueceu que estava numa cadeia.

Respondemos que os instrumentos poderiam entrar na prisão na medida em que estivessem discriminados na lista de autorização ${ }^{13}$. A partir disso, recebemos solicitações para perucas, brincos, relaxante de cabelo, papéis e canetas, roupas etc. Não tínhamos condições de realizar nenhum desses desejos.

Um dos pedidos mais emblemáticos veio de uma aluna que participou das primeiras aulas e que, depois, foi transferida ou recebeu alvará de soltura. Não conseguimos saber. Ela era a aluna mais velha da turma e pelo visto já tinha transicionado $^{14}$ há muito tempo. Jesus (2012) utiliza o termo processo transexualizador e o define como um

processo pelo qual a pessoa transgênero passa, de forma geral, para que seu corpo adquira características físicas do gênero com o qual se identifica. Pode ou não incluir tratamento hormonal, procedimentos cirúrgicos variados (como mastectomia, para homens transexuais) e cirurgia de redesignação genital/sexual ou de transgenitalização. (Jesus, 2012, p.30).

\footnotetext{
${ }^{13}$ No início desse semestre, para antecipar os pedidos, criamos uma lista hipotética de objetos e instrumentos que poderiam compor as atividades ao longo do ano. Nessa lista, solicitamos a entrada de muitos instrumentos, mas infelizmente Sax e Flauta não foram registrados. Especialmente porque não possuímos esse material no acervo do projeto.

14 Refere-se à transição de gênero. Esse foi o termo mais utilizado pelas participantes. Há outras leituras poéticas para esse processo, como, por exemplo, através dos termos transformação e revelação.
} 
A participante se empolgou ao saber que poderia usar nossos encontros para falar de sua história. Como ainda estávamos entendendo o número de alunas fixas e amadurecendo a proposta de trabalho para o semestre, foi difícil conciliar seu desejo com o do resto do grupo, que, no geral, queria conversar sobre os últimos acontecimentos da cadeia e saber mais sobre nós.

Se sentindo um pouco deslocada - as outras alunas a tratavam diferente, com um pouco de deboche às vezes, apelidando-a de “vovózona" -, expressava constantemente sua discordância da postura de outras integrantes durante as aulas. Com o passar dos encontros, se demonstrou cada vez mais irritada e, em alguns casos, não quis participar das atividades, ficando em um canto da sala, aguardando para avisar que precisaria conversar. Ela nos revelou que não era nascida no Brasil e passou boa parte da juventude no Iraque, seu país natal. Tinha trabalhado com o circo do Palhaço Carequinha e na TV, com o Palhaço Bozo. Ela se fantasiava da personagem Vovó Mafalda.

Ela sempre puxava algum/a de nós no canto para falar de gags e números que tinham aprendido com esses palhaços, e que gostaria muito de fazer uma demonstração nos nossos encontros. Para ela, o único modo de fazer teatro era retomando aquilo que sabia, com todos os detalhes e acessórios utilizados para a construção daquela "magia". Foi por isso que insistiu muito para que trouxéssemos a fantasia da Vovó Mafalda e uma lista extensa de acessórios que dificilmente entrariam na prisão sem uma autorização prévia. Infelizmente, não conseguimos permissão para desenvolver o trabalho com os elementos sugeridos por ela, mas suas memórias e histórias estavam sempre presentes nos improvisos que realizávamos ou nas criações textuais.

Em nossas conversas, percebemos um desejo comum em abordar a festa e o carnaval como temáticas centrais para o trabalho. Esses dois temas apareciam associados a uma demanda de "montação"15. Apesar de poderem exercer sua

15 Termo muito utilizado em nossas aulas para se referir à "comunicação da identidade de gênero que seria efetuada visualmente pela estética do corpo, com o auxilio da estética da indumentária” (Carneiro, 2019, p.358). A palavra pode ser facilmente associada às práticas de crossdressers, dragqueen ou drag king. É importante destacar as diferenças entre a utilização desse termo no nosso contexto de trabalho e nas práticas de crossdressers. Para os crossdressers, a montação está associada a um prazer pessoal de experimentação momentânea de um outro gênero. Sempre utilizamos esse termo para nos referirmos à 
expressão de gênero nessa prisão, não podiam se arrumar como gostariam. Uma das alunas afirmou que "é no carnaval que ficamos completamente livres, podendo ser quem nós somos, no meio da festa, e ninguém se mete com a gente. Ficamos invisíveis".

Apesar dessa consideração, não devemos desconsiderar o alto número de violência e assédio contra pessoas trans durante o carnaval ${ }^{16}$. Além disso, essa temática abre margem para um debate amplo e complexo. A ativista trans, Duda Salabert, em postagem no Instagram em fevereiro de 2020, comentou a decisão do Conselho Municipal de Promoção de lgualdade Racial de Belo Horizonte em liberar uma cartilha recomendando que homens não se vistam de mulher durante o carnaval. Para ela, a lógica da inversão é saudável no carnaval, mas, em alguns casos, acaba mobilizando uma visão caricata e inferior da mulher, reafirmando o machismo, misoginia e a transfobia. Ela ainda acrescenta que, para travestis, é muito desrespeitoso quando pessoas acham que elas estão fantasiadas. ${ }^{17}$

Villaschi, Alves e Rezende (2018), ao analisarem as territorialidades construídas por pessoas dissidentes sexuais e desobedientes de gênero em ruas específicas durante o carnaval de Ouro Preto, afirmam:

A rua, para além de um lugar de sociabilidade e de demarcação de relações sexuais e afetivas, é fruto da LGBTTQIfobia latente nas demais territorialidades. Assim, entender esse processo nos permite compreender seus enlaces com a situação dos LGBTTQIs em Ouro Preto e no Brasil. Viver e se divertir, para essas pessoas, é sobretudo resistir. Os corpos delas tornam-se políticos, à medida que preteridos e abjetos. Os seus "lugares", do mesmo modo, operam enquanto resistência numa sociedade hétero-compulsória. (Villaschi, Alves e Rezende, 2018, p. 229).

O comentário da aluna sobre liberdade dos corpos trans no carnaval, portanto, pode se referir a uma organização específica da comunidade, onde criam espaços de resistência contra o ClStema genocida existente. Podemos dizer que essa

urgência das participantes em expressar livremente sua própria identidade.

${ }^{16}$ Disponível em: https://catracalivre.com.br/carnaval-sem-assedio/violencia-e-assedio-contra-lgbtsaumentam-no-carnaval/ Acesso em: 05 dez. 2020.

17 "Cartilha pede que homens não se vistam de mulher no carnaval”. Postagem no Instagram em 13 fev. 2020. 
organização evidencia a "vivência rueira das trangeneridades” (Leal, 2020, p.13), pois é na "coralidade e coletividade" das ruas que se instaura uma potente resistência contra uma mentalidade normatizadora.

Algo similar é abordado por Jesus (2010), quando analisa a relação entre política e carnavalização nas Paradas do Orgulho LGBT, onde a aparência jocosa de diversão inaugura um espaço de resistência e atividade política. A ideia de festa se converte em fresta, produzindo territórios provisórios para a construção de "novas estratégias de construção da equidade e da visibilidade de gênero." (Toneli e Perucchi, 2006 apud Jesus, 2010, p. 162).

Essa perspectiva apresentada por Jesus (2010) também serve para a reflexão sobre as características das ações do nosso projeto. As participantes transformam aquele ambiente violento em uma fresta necessária. Além de ser um território criativo, é um espaço para o exercício de suas liberdades. É um espaço para celebração, para dançar, compartilhar histórias, falar sobre seus amores e desejos.

No primeiro momento, nossas aulas tinham uma sequência específica de atividades: começávamos com jogos teatrais ${ }^{18}$ - jogos de nomes, relação com o espaço, exercícios de escuta e breves meditações ${ }^{19}$ - e depois dançávamos. Logo nas primeiras aulas, durante nossos aquecimentos, percebemos uma necessidade coletiva pela dança. Isso atravessou todo o nosso processo.

Como não tínhamos como reproduzir música, sentimos a necessidade de trazer alguns instrumentos musicais. Conseguimos autorização para levar um pandeiro e isso foi fundamental desde os primeiros encontros até a apresentação final. É óbvio que o ritmo mais tocado foi o funk.

Resolvemos propor que as alunas organizassem uma constelação de desejos.

18 Esses jogos teatrais têm relação com a ideia de "exercícios estúpidos" proposta por Sotigui Kouyaté em sua visita ao Brasil em agosto de 2003. Segundo Bernat (2013), os "exercícios estúpidos", nome dado pelo próprio Sotiqui, propõem que reconheçamos na aparente banalidade desses exercícios que a "humanidade é permeada de fragilidade e força" (Bernat, 2013, p.153). Sotigui nos inspira a construir a própria estratégia em busca da consciência de si e das atitudes do homem em sua comunidade. Os "exercícios estúpidos" refletem bem a forma com que temos imaginado a condução no trabalho dentro do presídio, propondo continuamente novas "formas estúpidas" de autoconhecimento.

${ }^{19}$ Nos baseávamos no Sistema de Chakras e realizávamos exercícios respiratórios e meditativos mentalizando os Chakras que desejávamos trabalhar e as regiões do corpo associadas a eles. 
Queríamos experimentar organizar esses desejos tão falados em nossas conversas em um mapa, onde cada uma das participantes poderia destacar o que gostariam de fazer e falar, as temáticas que gostariam que fossem abordadas naquelas reuniões, suas necessidades e urgências e quaisquer outras referências. Na maior parte dos casos, demandaram produtos de beleza, objetos femininos e remédios. Algumas questionaram, inclusive, se tudo aquilo que listavam seria entregue no momento oportuno.

Fundar um território criativo de resistência dentro da prisão é uma atitude potente, mas deve estar sempre em relação com as preocupações e demandas que, sem dúvida, são urgentes. Isto também está exposto em Ferreira (2014), que destaca em seu livro a impossibilidade de travestis e seus companheiros realizarem certos debates sobre suas percepções sobre gênero e sexualidade porque, antes disso, precisam lidar com questões mais sérias, como a falta de sabonete ou pasta de dente.

\author{
Musicas. Boy Jorge - Estey Numbre Trée/ Nana Cayne - Volta no tempo \\ Palacos. Vovô Mafalda - Lirica \\ Boboletas. Coloridas \\ Vestidos. Roupa compridas \\ Filmes. Era uma no passado. / Um espirito baixou em mim \\ Desespero. remedios que não chega \\ Relegião. temas da resevados bo para alto estima. \\ (Constelação de Desejos, 2019)
}

O texto acima é a constelação de desejos criada pela aluna que solicitou que trouxéssemos os elementos para a sua caracterização como Vovó Mafalda. No texto, ela destacou alguns títulos de filmes e músicas que gostaria de ouvir algumas dessas músicas foram utilizadas em aula, executadas no violão ou cavaco - e, é importante ressaltar, denunciou a falta de assistência médica na prisão.

\title{
Objetos femininos
}

Nas primeiras criações, a maioria delas se referiram aos "objetos femininos" e ao desejo de "montação". O acesso limitado a alguns objetos era uma temática 
recorrente em suas reivindicações. A Resolução 558, de 2015, garante a livre identidade e expressão de gênero dentro das penitenciárias do RJ, mas a maior parte delas não possui recursos que garantam a aquisição de determinados objetos.

É importante dizer que a situação na Evaristo de Moraes se difere muito do que sabemos sobre outras prisões pelo Brasil, onde há uma violação sistemática dos direitos básicos das pessoas trans. Hoje, nossas alunas consideram a Evaristo de Moraes uma cadeia modelo no tratamento às trangeneridades, mesmo sem uma ala ou cela específica para essa comunidade.

O início do nosso trabalho coincidiu com a troca de diretor. Ficamos surpresos/as em saber que, logo na primeira semana, o diretor as reuniu para saber se gostariam de celas exclusivas, separadas dos homens. Quando uma das integrantes nos relatou a abordagem da diretoria, todas as outras reagiram quase que simultaneamente, afirmando que "se a gente ficar na mesma cela, vai ter que colocar uma SAMU ${ }^{20}$ na porta, vai ter briga todo dia”.

Destacamos a recorrência dos objetos femininos no nosso primeiro exercício e sugerimos um desdobramento a partir desse tema. Primeiro, pedimos que elas especificassem em uma lista todos os objetos pessoais desejados e os nomes das marcas dos produtos. Para nossa surpresa, as participantes foram além do que propusemos e sugeriram uma descrição detalhada dos objetos e dos produtos criados dentro do cárcere. Elas deram descrições surpreendentes sobre como criam seus próprios produtos de beleza. Uma delas, por exemplo, ensinou como produzir um rímel com a fumaça de um copo plástico queimado. Uma outra participante ensinou como transformar uma cueca em uma blusa sem alça. Além dos objetos, as alunas começaram a dar descrições sobre como deveriam "esconder a neca" ou "tirar o xuxu". ${ }^{21}$ Todas essas eram estratégias utilizadas para fazer resistir o feminino em um espaço com tantas restrições.

\footnotetext{
20 Serviço de Atendimento Móvel de Urgência.

21 "Esconder a Neca" significa esconder o volume do pênis entre as pernas. "Tirar o Xuxu" significa retirar todos os resquícios de barba. Geralmente as alunas se referiam a essa ação fazendo movimentos que indicavam a utilização de um espelho e uma pinça.
} 


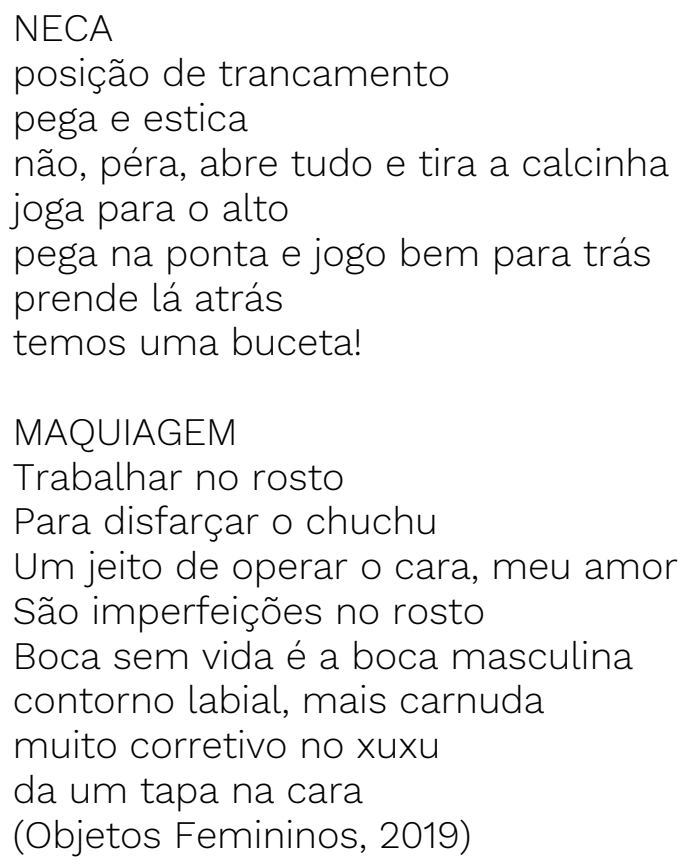

O mote para a nossa próxima etapa surgiu a partir de um improviso que apresentava ações com objetos encontrados em um salão de beleza. Esse jogo fez com que elas compartilhassem suas experiências em salões de diversos países. Tivemos uma longa conversa sobre o que esse lugar significava para cada uma delas e descobrimos que muitas trabalharam nesses espaços em algum momento da vida. De fato, o salão é um reduto de proteção importante na trajetória delas. Para algumas foi a única opção de trabalho, caso contrário estariam na prostituição.

\section{Quem sou eu no salão?}

Começamos a propor um aprofundamento dessa atmosfera do salão em todos os exercícios que realizávamos. Mas antes, elas solicitaram que trouxéssemos mais informações sobre direitos específicos das travestis, com destaque para a condição desse grupo no cárcere, e também para "conhecer umas monas famosas".

Separamos um conjunto de quarenta matérias de jornais com diferentes assuntos, especialmente aquelas que destacavam o trabalho de importantes 
lideranças trans e reflexões recentes sobre os direitos das pessoas dissidentes sexuais e desobedientes de gênero e suas especificidades nas prisões.

Separamos a turma em dois grupos e pedimos que escolhessem uma matéria de interesse e, se possível, realizassem observações sobre sua escolha com o resto do grupo. Depois, cada grupo decidiu trabalhar sobre uma única matéria, que foi estímulo para a construção de cena naquele mesmo dia de aula. As reportagens selecionadas abordavam processos de hormonização e transição de gênero na infância. A primeira cena foi organizada como um tutorial de hormonização. Três alunas se posicionaram lado a lado como se estivessem numa vitrine, cada uma com uma posição específica. Uma delas, destacada do trio inicial, começou a narrar as transformações que o corpo sofre depois do início do tratamento hormonal, enquanto isso as outras executavam ações que tinham a ver com as transformações narradas.

O segundo grupo apresentou uma cena que se passava em um púlpito de igreja, onde o pastor insistia em tirar o demônio de uma criança trans que tentava convencer os/as outros/as de que ela estava bem e normal. As cenas foram seguidas de debates coletivos sobre hormonioterapia dentro da prisão e dentro do círculo social de algumas das alunas. Uma delas relatou ter diversas amigas que se automutilaram, fora da cadeia, por não suportarem ter um órgão genital que não corresponde a sua identidade de gênero.

Também conversamos sobre a falta de orientação médica no processo transexualizador, o que leva boa parte das mulheres trans a se automedicar excessivamente. O resultado disso é o desencadeamento de diversas doenças provocadas pelo uso excessivo e não controlado de hormônios. Apesar de saberem que existem orientações e atendimentos pelo SUS ${ }^{22}$, é muito difícil conseguir vagas e, quando conseguem, ainda sofrem uma série de humilhações e preconceitos, como a falta de orientação e capacitação da equipe de atendimento

22 "O recurso à hormonoterapia, embora recentemente regulamentado pela Portaria n. 2.803 de 19 de novembro de 2013 do Ministério da Saúde, que redefine e amplia a possibilidade de uso orientado de hormônios também por travestis, fica restrito ao processo transexualizador do Sistema único de Saúde (SUS), o que significa que toda pessoa trans, para ter acesso ao processo transexualizador (e, por extensão, à orientação médica quanto ao uso de hormônios femininos), precisa acessar os programas dos hospitais que tematizam essa questão." (Ferreira, 2014, p. 106). 
para lidar com o uso do nome social que é fator crucial para a inclusão das identidades de gênero.

Dentro do cárcere, portanto, o acesso aos hormônios para aquelas que não estão cadastradas no programa do SUS dependem do investimento pessoal, quando a família é autorizada a trazer os remédios através da custódia e, mesmo assim, tal como nos foi dito por uma delas, não raro esses medicamentos são extraviados em parte ou totalmente. Outras alunas sugeriram a substituição da hormonização por intervenções cirúrgicas, o que logo foi ponderado por algumas delas, que apontaram os riscos das intervenções com silicone industrial em clínicas clandestinas e sem estruturas adequadas.

O exercício do grupo número dois acabou desencadeando relatos sobre os momentos em que as participantes "transicionaram" em suas vidas. Algumas contaram histórias de "revelação" dentro do cárcere - o que é muito comum destacando que elas se sentem apoiadas por outras travestis, e, portanto, encorajadas a viver como realmente se identificam.

Em seguida, uma das participantes sugeriu que o grupo discutisse sobre a transferência para presídios femininos. Apesar da decisão proferida pelo ministro Luís Roberto Barroso em 2019²3, autorizando a transferência de pessoas trans para penitenciárias femininas, não há consenso entre a maioria delas sobre esse assunto. Além disso, é bom destacar que a decisão apresenta uma diferenciação entre travestis e mulheres trans, e só garante a transferência para aquelas inseridas no segundo grupo. Essa divisão incorre no que Leal (2020, p. 7) chama de "aberrante diferenciação de pessoas trans (a expressão trans e travesti): criada pelo Estado para denotar com legitimidade institucional, para que não haja dúvida sobre quem é mais trans do que quem".

As participantes justificaram que não saberiam dimensionar a opinião das mulheres cisgênero encarceradas sobre esse assunto. Além disso, elas alegaram que teriam pouca atenção às suas especificidades - como, por exemplo, a manutenção da terapia hormonal. Para elas, era melhor não dividir certas

23 Disponível em: https://oglobo.globo.com/sociedade/barroso-manda-transferir-mulheres-trans-presaspara-unidades-femininas-23766594 Acesso em: 05 dez. 2020. 
demandas com um número enorme de mulheres, o que é mais fácil de administrar em um presídio como o Evaristo de Moraes, com 90 travestis.

Elas também se contrapuseram às transferências por conta das relações com os companheiros de celas - algumas delas possuem marido ou namorado há anos. Sobre esse assunto, ainda reiteraram que em uma penitenciária com dominações de facções criminosas, especialmente o Comando Vermelho e o Terceiro Comando, as principais facções do Rio, o tratamento humanitário é comprometido, visto que cada facção tem seu regimento interno sobre aceitar ou não as dissidências sexuais e desobediências de gênero. No caso da Evaristo de Moraes, por exemplo, não há essa preocupação, pois a penitenciária é considerada uma "unidade seguro", ou seja, não recebe internos/as com envolvimentos com essas facções.

Além das matérias de jornal selecionadas pelos grupos, utilizamos outra como dispositivo para a criação textual. Uma nova reportagem mostrava o trabalho desenvolvido por um grupo de travestis em um salão de beleza em Buenos Aires, em 2016. ${ }^{24}$ A foto de capa da reportagem fez muito sucesso algumas delas pediram cópia para guardar de recordação em suas celas. A partir dessa imagem elas começaram a inventar histórias, personagens e relações. Quem sou eu no Salão? era a frase/dispositivo. Sugerimos a criação de personagens que endereçariam cartas e mensagens às criadoras do salão. Algumas delas resolveram escrever textos assinados por clientes, funcionários do salão, fornecedores/as, proprietária do estabelecimento e o presidente, como podemos ver a seguir:

Bom dia a todas, venho em meio desta carta parabenizar a todas vocês por essa iniciativa, onde todos que chega são bem tratados. Tenho recebido muitos elogios de vocês, aqui. Quero com isso audar a amplar o projeto, pois sei assim poderiamos ajudar mais e mais pessoas, tanto, com a beleza inferior e também a interior. Pois isso é muito importante para nossa sociedade e quero a população GLBT seja mais presente em recições publica para que a sociedade aprenda a respeita o espaço um do outro desde já muito obrigado.

Assinado o presidente

(Quem sou eu no salão?, 2019)

24 Disponível em: https://www.efe.com/efe/brasil/sociedade/primeiro-sal-o-de-beleza-trans-da-argentinafecha-a-porta-para-prostitui/50000246-3135551 Acesso em: 12 out. 20. 
O texto reivindica a participação pública e política das vivências trans, e, além disso, evidencia afirmações que se contrapõem ao discurso de ódio propagado por lideranças políticas que compõem o governo brasileiro.

\section{Hoje vou ao salão porque amanhã é um dia importante}

As alunas receberam o dispositivo do dia (o enunciado "hoje vou ao salão porque amanhã é um dia importante"), e a partir dele que desenvolveram o exercício de escrita. No entanto, dessa vez, invertemos a ordem das proposições, sugerindo que a baliza para a criação fosse primeiramente experimentada na cena. Escolhemos um espaço na sala e demarcamos um território de jogo com uma fita crepe - começamos a sugerir que elas se preocupassem com a utilização de toda a arquitetura daquela sala como estímulo para as improvisações. Elas iniciaram as narrativas e, em determinado momento, uma ou mais entraram em cena para acrescentar informações na história inventada. Nós e as alunas que não estavam em cena interagíamos com perguntas e sugestões de ocupação daquele espaço recortado. Em alguns casos, as alunas construíram histórias a partir de uma posição e forma do corpo no espaço. No final da experiência, elas utilizaram as imagens e narrativas desenvolvidas na cena como um ponto de partida para a escrita, convocando elementos do seu próprio trabalho ou com inspirações nos trabalhos observados. Nessa etapa, as participantes utilizaram o enunciado para o compartilhamento de memórias de dias marcantes em suas vidas e destacaram a saudade que sentiam da família ou de situações que viveram com eles/as:

\section{// Debutante}

Amanhã será o aniversário de Maria Eduarda, ela fará 15 anos. Minha querida prima, está uma adolescente linda! Hoje ela virá aqui no salão para fazer a prova do cabelo e da maquiagem, eu pedi para ela trazer a coroa e o vestido para tirarmos fotos. Enfim o resultado ficou lindo, ela parecia uma verdadeira princesa. Ela ficou tão deslumbrada com o trabalho, que queria dormir arruma e maquiada.

Seu aniversário foi realmente um dia de princesa.

Arreasei!

(Hoje vou ao salão porque amanhã é um dia importante, 2019) 


\section{O que está por trás das fotos?}

Selecionamos diversas fotografias de procedimentos estéticos dos anos quarenta, cinquenta e sessenta e sugerimos que as alunas as utilizassem como enunciado para o próximo exercício. Pedimos que elas escolhessem uma fotografia e imaginassem qual situação poderia estar por trás delas: Quem são essas pessoas? O que elas estavam fazendo no momento da foto? Do que elas gostam? O que elas têm pensado? O que estavam fazendo momentos antes daquela foto? Como chegaram até aquele local onde a foto foi tirada?

As alunas levaram um longo tempo escolhendo e debatendo sobre as situações das fotos, inventando coletivamente algumas possibilidades de histórias para cada uma delas. Por conta dessa atividade, uma delas saiu da sala, às pressas, para ir até a cela e buscar uma fotografia sua com uma peruca idêntica à da fotografia escolhida. Elas ficaram extremamente apegadas às fotografias e pediram muito que pudessem ficar com os materiais para elas. E é óbvio que ficaram.

Nesse período, nossas atividades começaram a acontecer na sala da escola. Em algumas circunstâncias, a escola precisa utilizar a sala de ensaio - o auditório Anacleto de Medeiros - para a aplicação de provas e outras atividades. No entanto, isso não nos prejudica tanto. Pelo contrário, nas salas de aula da escola as atividades costumam ser mais concentradas, pois temos a possibilidade de fechar a porta, diminuir o barulho do resto da cadeia e bloquear a visão para o corredor central. Nos dias de nossa aula, às sextas-feiras, a penitenciária recebe novos/as presos/as, e o procedimento de revista ocorre na porta do auditório onde trabalhamos. Não raramente as alunas se dispersam, abandonando as atividades e se agrupando em frente à porta, curiosas para saber quem são as novas pessoas que estão entrando na prisão. É através da reação delas que conseguimos perceber a reincidência de algumas travestis. Sempre que avistam alguém que já tenha passado pelo C/Stema, elas gritam: "ih, fulana voltou!".

O trabalho com as fotos desencadeou o interesse em produzirmos uma 
sessão de fotografias reproduzindo as imagens escolhidas pelas alunas. Sabíamos que seria difícil conseguir todos os objetos ilustrados nas fotos, e por isso começamos a elaborar adaptações. Uma das alunas comentou que poderíamos substituir as cúpulas de secar e modelar cabelo, que apareciam em diversas fotografias, por baldes. O grupo estava entusiasmado com a possibilidade de organizarmos um dia de beleza, com perucas, vestidos e maquiagens. Sabíamos da dificuldade em termos autorização para a entrada desses materiais, mas tínhamos a esperança de conseguir caso apresentássemos uma proposta melhor estruturada, dando justificativas embasadas em nossas investigações artísticas. Apesar de termos elaborado um documento explicando todas as referências e necessidades da nossa proposta, tivemos nosso pedido negado pela SEAP, tanto para a lista de materiais como para a entrada de câmera fotográfica.

O texto a seguir foi construído pela mesma participante que lembrou da peruca que utilizava quando estava em liberdade. A sua recordação e descrição sobre o cabelo - textura, tamanho, peso - fez com que desenvolvêssemos uma sequência coreográfica que explorava diversas ações que remetiam à imagem escolhida e ao ato de pentear. 
Figura 1 - Fotografia utilizada como estímulo para a criação 0 que está por trás da foto? ${ }^{25}$

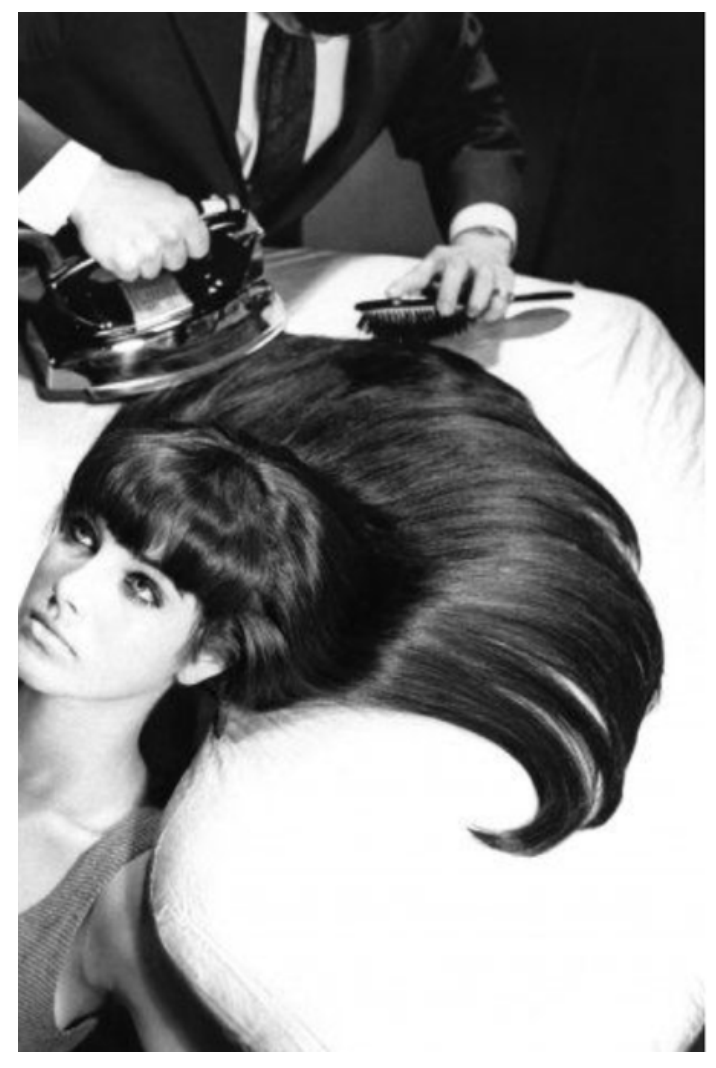

\section{O QUE TEM POR TRAS DA FOTO?}

De LARISSA

Eu estava passando na Lapa com meu cabelo pranchado, começou a chover e meu cabelo encolheu. Então, resolvi fazer um pente quente, queria ficar com o cabelo igual da Maria Bethania. Fiz o pente quente e meu cabelo ficou liso. Fiquei Bethania. Fiz o pente quente e meu cabelo ficou liso. Fiquei
bonita. Eu só queria ficar com o cabelo iual de uma india, já tenho a cor. Segui caminhando para copacabana, lá encontrei um ator. Ele me parou e perguntou para onde eu ia, e disse que era para o posto 5 . Ele me convidou para ir em uma balada, ele admirou meu cabelo e minha cor, cantamos juntos, curtimos muito a música eletrônica, e, no final da festa, fomos dormir em um motel. Quando acordei, ele pensou que eu fosse dormir em um motel. Quando acordei, ele pensou que eu fosse
uma mulher. Falei para ele que era, mas também não era. Ele estranhou, mas eu já havia filmado e postado no instagram.

Fonte: In: https://pin.it/5fwcFnV Acesso em: 05 dez.2020

\section{Como montar uma travesti}

São muitas as atitudes que desencorajam as mulheres a reivindicarem seus direitos por expressão de gênero. No geral, as mulheres são colocadas na categoria "homossexuais", e isso, portanto, inviabiliza um debate ampliado sobre gênero. Ao se referir a elas como homossexuais, fica evidente que a instituição só considera - e de uma forma muito rasa - aspectos da sexualidade.

Ocupar o espaço de aula com corpos cada vez mais femininos, com debates sobre o embelezamento e aprimorando seus modos de expressão de gênero, nos ajuda a demarcar uma ação de resistência frente a essa divisão muito simplista proposta pela a instituição. A montação é um ato de resistência contra a

25 Essa composição de texto e imagem foi utilizada para a dissertação Tráfico-Teatro: Percurso de Desobediência à Cisnormatividade Carcerária (UNIRIO), de Sergio Costa Junior (Sergio Kauffmann). 
cisnormatividade e nos ajuda a promover um debate mais amplo sobre a travestilidade ${ }^{26}$. Mas isso não pode ficar restrito às nossas aulas. Atribuir a prática de montação ao espaço e tempo das aulas de teatro pode nos colocar em risco de convencionar que aquele ou tal modo de ser tem relação com as propostas do "teatrinho", que é como alguns agentes se referem pejorativamente às aulas de teatro, e que, portanto, deve ficar circunscrito àquela experiência "exótica" para uma instituição feita para punir. Elas querem e precisam muito mais do que isso.

Na medida em que intensificamos o debate sobre a montação, começamos a perceber que estávamos ignorando parte da turma que não se declarava travesti. Logo nas primeiras semanas, detentos que se reconheciam como gays solicitaram a participação nas aulas de teatro, pois não se sentiam à vontade para participar das atividades de terça-feira, também do nosso projeto, mas dedicada aos homens cis. Precisávamos reconfigurar a proposta do nosso trabalho, tentando abarcar as necessidades da comunidade dissidente sexual e desobediente de gênero como um todo. Apesar disso, as demandas e narrativas construídas nos nossos encontros evidenciaram as necessidades apontadas pelas travestis.

Algumas das nossas alunas não se consideram travestis fora do cárcere. Elas já se posicionaram afirmando que os nomes femininos assumidos ali fazem parte de uma construção identitária específica para a vida na prisão. De alguma maneira, assumir essa nova identidade garante uma proteção, de modo inverso ao Cisplay, que também é uma estratégia de proteção abordada por muitas delas. Leal (2020), ao dissertar sobre "a violência ambiental às transgeneridades", termo alternativo à "transfobia” por considerar que este carrega uma carga patológica atribuída ao opressor e torna difusa a compreensão de que as violências se relacionam com uma configuração moral (opressão), aborda o cisplay como estratégia de proteção contra as condições cisnormativas.

Cisplay é uma configuração espacial que leva o segredo à rua, a todos os lugares onde a pessoa desobediente de gênero está ou quer estar. a

26 Termo utilizado para referir-se aos aspectos identitários da pessoa travesti. Jesus (2012) elabora uma concisa definição sobre o que é ser uma pessoa travesti: "são travestis as pessoas que vivenciam papéis de gênero feminino, mas não se reconhecem como homens ou como mulheres, mas como membros de um terceiro gênero ou de um não-gênero". (Jesus, 2012, p.17). 
intenção do querer estar como fundamental para compreensão do cisplay como modo protetivo: muitas pessoas trans recorrem a este artifício hoje para poupar-se de interpelações em ambientes diversos como os espaços burocráticos, médicos, a compra de passagem terrestre e aérea, etc. (Leal, 2020, p.15).

Apesar desse fluxo identitário, não percebemos ninguém se posicionando contra aquelas que não se identificavam como trans. Especialmente porque algumas delas, que hoje se reconhecem como travestis, também passaram por processos parecidos até realizarem o processo transexualizador. Quando a transição é realizada na cadeia, há uma grande rede de apoio e aconselhamento, quase como uma iniciação, que, inclusive, é chamada por elas de "batismo".

Propusemos que elas começassem a escrever a partir do dispositivo Como Montar Uma Travesti. Nesta dinâmica, percebemos a intensificação de algumas diferenças, em especial quando depositavam toda a possibilidade de ser mulher em procedimentos estéticos que, para a maioria delas, não era possível fazer.

Alguns textos apontavam para uma glamourização da mulher, como uma única opção de exercício de sua identidade. Outras falaram claramente que "sem prótese, não dá" ou que "quanto mais injetável melhor". Contrapondo-se a isso, uma delas escreveu sobre como se percebe mulher desde muito cedo, e que ao longo da vida encontrou diversos modos de percepção de sua identidade, independente da vestimenta ou da quantidade de silicone.

Primeiro: um procedimento estético de feminização e caracterização; Segundo: Se portar e comportar como uma trans;

Terceiro: Transformação nas vestimentas e acessórios de masculinos para feminino;

Quarto: Uma mega produção para a total caracterização.

Mais importante que se montar é saber que tudo pode ser transformar desde que a sua necessidade seja ser e se comportar como tal. Podemos dizer que muitas ainda não passaram por certos tipos de procedimentos estéticos por causa de condições calaras (familiar) e entre outras, mas a real transformação está em você mesma.

EX: a questão ser ou se portar ou se comportar.

(Como montar uma travesti, 2019) 


\section{nome social}

Nos últimos meses de trabalho, a pesquisadora Vicentina Flôr começou a participar das ações. A sua presença foi fundamental para, de alguma forma, reestruturar nosso modo de trabalho. Sua chegada estimulou as participantes a refletirem sobre a nossa presença e propósito naquela prisão. Depois que se apresentou - e fez isso cantando a música Senzala, da MC Xuxu²7 - começamos a perceber, pela primeira vez, uma curiosidade coletiva em saber como eram as dinâmicas do projeto. Queriam saber se éramos voluntários/as, como era o processo de entrada na universidade, e, principalmente, como era para ela ser uma travesti na universidade.

Como a apresentação estava muito próxima e não tínhamos garantia de que conseguiríamos ensaiar nos dias agendados para as aulas, começamos a estruturar um roteiro a partir dos materiais que tínhamos construído até aquela etapa. Primeiro, organizamos uma possível cena de inauguração do salão a partir de uma dinâmica semelhante ao jogo da tradução ${ }^{28}$, muito comum na palhaçaria. Espalhamos pela sala os textos escritos por elas para o Como Montar Uma Travesti e pedimos que escolhessem alguns trechos que pudessem ser utilizados na improvisação. Organizamos o jogo com diversas duplas que se dividiram entre Tradutora e Especialista.

A especialista deveria apresentar os trechos escolhidos em gromelô, como uma língua inventada, enquanto era traduzida. Depois da apresentação das duplas, definimos juntos/as quais outras personagens poderiam aparecer naquela cena: a dona do salão, a tradutora, a intérprete, as modelos que seriam montadas e um coro, que ficaria posicionado na lateral da cena e reagiria ao processo de

${ }^{27}$ Eu cresci ouvindo que as portas não se abririam / Minha mãe sempre falou pra eu não ligar pro que diziam / Bpm dos tiros me ajudando a compor / Hoje eu posso dizer de onde eu vim e pra onde eu vou / Não sou manipulada eu vivo a realidade / Mas me julgam como se fossem os donos da verdade / Mulher de peito pau e seu conceito não me abala / Eu sou favela aceita o brilho da senzala / Quase nunca sou bem-vinda, onde eu chego causo pane / Mas eu sei / que eu sou linda e quero mais é que se danem / Mulher de peito pau e seu conceito não me abala / Eu sou favela, o brilho da senzala / Olha pra ela: o brilho da senzala.

${ }^{28}$ Ver a descrição em Achcar (2007). 
montagem, concordando ou discordado com as escolhas feitas pela especialista. O modo como a cena foi construída permitiu que permanecêssemos em debate mesmo quando repetíamos a estrutura. Era como um Teatro-Fórum, metodologia desenvolvida por Augusto Boal.

Não seguimos as etapas de elaboração do Fórum e nem trabalhamos para a resolução de uma situação de opressão específica. Mas a cena construída tinha uma abertura necessária para as intervenções das alunas - principalmente as recém-chegadas nas aulas - que gostariam de apresentar diferentes perspectivas sobre como montar uma travesti.

No final de cada apresentação, uma das alunas - que ficou responsável pelo papel da tradutora - propôs que as outras, que estavam na periferia da cena ou na plateia, fizessem perguntas para a especialista. Essa interação fez com que mantivéssemos o jogo muito vivo, exigindo que a tradutora construísse modos diversos e espontâneos de traduzir as perguntas para a intérprete. Nesse momento, Flôr provocou: "O que fazer para ser uma travesti quando não temos dinheiro para realizar essa montagem toda aí"? Uma das alunas pediu para entrar na cena e começou a defender como essa montação poderia acontecer para além dos procedimentos que elas narravam.

Flôr também propôs que ensaiássemos para cantar juntos/as a música Senzala. De fato, as alunas ficaram bem empolgadas com a possibilidade de apresentar a canção, e ainda sugeriram uma paródia para Beijinho no Ombro ${ }^{29}$, música com uma melodia muito conhecida e que a maioria delas já sabia de cor. O interesse delas pelas músicas nos ajudou a levar para cena o que tanto repetimos ao longo do processo, já que sempre encerrávamos nossas aulas cantando juntos/as.

Nossos encontros finais foram dedicados ao ensaio dessas duas músicas e da cena de abertura do salão. Depois, começamos a compartilhar as histórias dos nomes, e isso se fundiu com as danças que construímos ao longo do processo. Utilizamos o pandeiro para marcar um ritmo de funk, e, assim, cada uma das

${ }^{29}$ Música de Wallace Vianna e André Vieira gravada pela cantora de funk Valesca Popozuda. 
participantes tinha seu tempo para dançar, escolher interromper a música como quisesse e contar brevemente a história do seu nome social.

Tínhamos muitos planejamentos sobre como poderíamos sugerir cenas/ações performáticas a partir dos textos criados por elas. Mas o trabalho na prisão tem seu ritmo próprio, nem sempre podemos entrar para trabalhar e, quando entramos, precisamos priorizar a construção de um território de cuidado. Mas é preciso reconhecer certos dilemas, pois parece uma equação simples, mas não é. Em muitos momentos vivemos na linha tênue entre "o que poderíamos fazer com elas" e "o que estamos vivendo com elas". Não são poucas as situações em que nos vemos como professores/as debatendo o que poderia ser bom para o espetáculo sem saber antes o que elas realmente estão dispostas e interessadas em fazer. É óbvio que as alunas estavam muito empolgadas com a apresentação e estimuladas a apresentar, mas talvez devêssemos nos esforçar para cuidar das relações ao invés de "atropelar tudo" para concretizar a apresentação final.

\section{A apresentação}

Esperávamos reunir cerca de 90 pessoas no auditório. Conseguimos autorização para entrar com salgadinhos e alguns refrigerantes para nossa confraternização de fim de ano. Os alunos de terça-feira - que também apresentaram a finalização do trabalho nesse mesmo dia - chegaram a fazer uma "vaquinha" para a compra de um bolo do tamanho de uma porta - sem exageros. Dentro da cadeia há um serviço de culinária e confeitaria. O serviço é extremamente caro e um bolo de laranja pequeno costuma custar cinquenta reais. Tendo como base esse preço é possível prever que os alunos estavam dispostos a pagar muito caro pelo bolo gigante.

Chegamos cedo com as comidas e fomos avisados/as pelo agente de segurança que um procedimento interno atrasaria nossa entrada, ou pior, que talvez nem entrássemos. Como já estávamos acostumados/as com a dinâmica da cadeia, desanimamos, já convencidos/as de que talvez fosse necessário remarcar a apresentação final. Poucos minutos depois, o diretor chegou e comentamos 
sobre ocorrido, já interessados/as em remarcar a apresentação e garantir a entrada dos alimentos. Ele respondeu rispidamente que não estava sabendo de procedimento algum. Dirigiu-se à porta de entrada, falou algo com o guarda, e em seguida nos chamaram para conferir as comidas através da custódia. Percebemos que o "procedimento" na verdade era uma má vontade de realizar a vistoria de entrada nos produtos.

Chegamos no auditório e mais uma surpresa: somente os alunos de terçafeira tinham sido liberados. Cerca de duas horas depois as senhas das alunas ainda não tinham "batido"30. Como sempre, o problema acaba prejudicando o elo mais fraco do ClStema, e os alunos homens conseguiram "fazer barulho" suficiente para serem liberados com prioridade.

A sala estava extremamente cheia e não tínhamos mais como esperar para começar - e também já tínhamos pouco tempo até a hora de ir embora. Já estávamos quase convencidos/as de não apresentar, mas as alunas começaram a sair de suas celas, aos poucos.

O problema é que as alunas liberadas para a apresentação eram alunas novas, interessadas em participar do teatro, e achavam que era o primeiro dia de aula. Presumimos que os guardas, pressionados pelo atraso, gritaram a esmo na porta das celas sem consultar a lista de participantes. Saíram todas as pessoas interessadas em teatro, e, por último, as nossas alunas.

Nos reunimos em um canto da sala para conversar sobre a apresentação, esquematizamos tudo e dividimos as personagens. Elas subiram ansiosas no palco e começaram a improvisar interações com a plateia. Depois de um tempo, iniciaram as cenas de apresentação dos nomes. Uma mulher - desse novo grupo que chegou achando que era o primeiro dia de aula - ficou tão empolgada que resolveu espontaneamente subir no palco para dançar e contar o seu nome. Ela "dançou até o chão" e foi ovacionada.

Depois da cena de inauguração do salão, umas das alunas disse: "Vocês viram aqui como se monta uma travesti! Simples, né? Quem quiser pode virar uma”. Os

${ }^{30}$ É como agentes se referem às senhas quando elas saem da sala se segurança para a distribuição e liberação. 
homens riram e aplaudiram. Tinha uma felicidade evidente, uma sensação de celebração de liberdade e participação.

Não podemos negar o quanto ficamos um pouco frustrados/as por conta do quase cancelamento, e também por não termos tido o tempo necessário para preparar toda a estrutura desejada pelas alunas, a montação e a maquiagem, principalmente. Pensávamos em cenário, em utilizar as fotos que as alunas tinham escolhido, em expor todos os textos do processo em um varal, em ensaiar nas semanas anteriores com o tempo integral de aula - nosso último ensaio foi duas semanas antes da apresentação -, mas nada disso foi possível. Apesar de todas as adversidades, aprendemos que é possível fundar um território criativo com muito pouco.

A nossa presença, juntos/as, já é um ato de resistência fundamental. Escutar e aprender com o que essas mulheres têm a dizer, dia a dia, seus cansaços, músicas, pajubás e desejos é a maior celebração possível da potência do teatro naquele espaço como estratégia de denúncia contra a cisnormatividade carcerária. Com o tempo, fomos fortalecendo um circuito sensível de afetos que nos permitiu idealizar coisas incríveis para um espaço tão árido. Preferimos pensar que não deixamos de realizar nada, mas que já indicamos o quanto será possível para os próximos encontros.

Como visto em Kauffmann (2019, p.112), a construção de um salão de beleza exclusivo para as travestis foi autorizada pelo diretor da penitenciária. Talvez nossa produção artística tenha sido o estopim para que essa pauta ficasse cada vez mais evidente. Não sabemos ao certo como essa influência aconteceu. É certo que nos últimos meses, além de marcarmos presença em nosso espaço de produção artística, reforçando a necessidade de atividades regulares para essa comunidade, nos engajamos na resolução de pequenos problemas: seja ajudando a quebrar a invisibilidade desse grupo para a escola, incluindo nomes na lista de matrícula, ou simplesmente parando para celebrar as narrativas e vivências apresentadas por elas, podendo, inclusive, garantir a elas o nosso engajamento em compor uma rede de apoio que as receberá depois do período de privação de liberdade; e usaremos o espaço da universidade pública para isso. Nosso encontro continuará sendo 
corrosivo.

\begin{abstract}
Beijinho no ombro, sou travesti com orgulho /Beijinho no ombro, nem venha com preconceito, não /Beijinho no ombro, do meu salto eu não desgrudo /Beijinho no ombro, só glamour e ostentação/Beijinho no ombro, esse salão vai ser tudo /Beijinho no ombro, tô louquinha pra inauguração/Beijinho no ombro, vou produzida no luxo/Beijinho no ombro, todas na hormonização.

(Paródia de Beijinho no Ombro, 2019).
\end{abstract}

\title{
Referências
}

ACHCAR, Ana. Palhaço de Hospital: Proposta Metodológica de Formação. 2007. Tese (Doutorado em Artes Cênicas) - Centro de Artes - Universidade Federal do Estado do Rio de Janeiro, Rio de Janeiro, 2007.

BERNAT, Isaac. Encontros com o griot Sotigui Kouyaté. Rio de Janeiro: Pallas, 2013.

CARNEIRO, Taya. Montação: moda na comunicação da identidade de gênero. Salvador: Periódicus, n. 11, v.1, maio-out, 2019.

FERREIRA, Guilherme Gomes. Travestis e Prisões: experiência social e mecanismos particulares de encarceramento no Brasil. Curitiba: Multideia, 2014.

GOFFMAN, Erving. Manicômios, Prisões e Conventos, São Paulo, Perspectiva, 1974.

JESUS, J. G. Introdução. In G. G. Ferreira, Travestis e prisões: experiência social e mecanismos particulares de encarceramento no Brasil. Brasil, Curitiba: Multideia, 2014.

JESUS, J. G. O Protesto na Festa: Política e Carnavalização nas Paradas do

Orgulho LGBT. 2010. Tese (Doutorado) - Universidade de Brasília, Brasília, 2010.

JESUS, Jaqueline Gomes de. Orientações sobre identidade de gênero: conceitos e termos. Brasília: E-book, 2012. Acesso em: http://issuu.com

KAUFFMANN, Sergio. Uma Plataforma de Resistência: O Teatro e a Escrita Criativa com Mulheres Transgênero Encarceradas. In: Carla Cruz, Hugo Cruz, Isabel Bezelga, Miguel Falcão e Ramon Aguiar. (Org.). Em Busca do Comum: Práticas Artísticas Para Outros Futuros Possíveis. 1ed.Porto: i2ads - Instituto de Investigação em Arte, Design e Sociedade, 2020, v. , p. 107-114.

LEAL, Dodi Tavares Borges. Performatividade transgênera: equações poéticas de reconhecimento recíproco na recepção teatral. 2018. Tese (Doutorado em Psicologia Social) - Instituto de Psicologia, Universidade de São Paulo, São Paulo, 
2018.

LEAL, Dodi Tavares Borges. Espacialidade travesti: habitat de gênero e práticas topográficas de corpos trans nas artes da cena brasileira. Urdimento, Florianópolis, v.2, n. 38, p.1-19, 2020.

MOMBAÇA, Jota. Rumo a uma redistribuição desobediente de gênero e anticolonial da violência. In: Caderno de Imaginação Política. São Paulo: Fundação Bienal de São Paulo, 2016.

Primeiro salão de beleza trans da Argentina fecha a porta para a prostituição. Agencia EFE, 2016. Disponível em: https://www.efe.com/efe/brasil/sociedade/primeiro-sal-o-de-beleza-trans-daargentina-fecha-a-porta-para-prostitui/50000246-3135551Acesso em: 14 maio 2020.

REZENDE, Y. A. E. Alves, K. S. Villaschi, J. N. S. Corpos dissidentes na rua: Territorialidade e identidades acionadas no carnaval de Ouro Preto (MG). Revista Periódicus. Salvador, v.1. n. 8, 2017.

SALABERT, Duda. Cartilha pede que homens não se vistam de mulher no carnaval. Instagram, 13 fev. 2020. Acesso em:

https://www.instagram.com/p/B8hxWDHpd8h/?utm source=ig web copy link

\section{Relatórios}

DEFENSORIA PÚBLICA DO ESTADO DO RIO DE JANEIRO. Nudiversis, 2020. Disponível em http://www.defensoria.rj.def.br/Cidadao/NUDIVERSIS Acesso em 15 de maio de 2020.

BRASIL, Ministério da Justiça, Levantamento Nacional de Informações Penitenciárias. Atualização junho de 2017. Departamento Penitenciário nacional, 2019. Acesso em: https://www.gov.br/depen/pt-br/sisdepen/maisinformacoes/relatorios-infopen/relatorios-sinteticos/infopen-jun-2017.pdf

BRASIL, Ministério da Mulher, da Família e dos Direitos Humanos. LGBT nas Prisões do Brasil: Diagnóstico dos Procedimentos institucionais e experiências de encarceramento. Departamento de Promoção dos Direitos LGBT, 2020.

MECANISMO ESTADUAL DE PREVENÇÃO E COMBATE À TORTURA DO RIO DE JANEIRO. Relatório Mulheres, Meninas e Privação de Liberdade no Rio de Janeiro, 2016. Disponível em http://mecanismorj.com.br/relatorios/.

RELATÓRIO DA DEFENSORIA PÚBLICA DO ESTADO DO RIO DE JANEIRO. Inspeção no Presídio Evaristo de Moraes. Núcleo de Defesa em Direitos Humanos, 2015. Disponível

em: http://www.defensoria.rj.def.br/uploads/arquivos/4489b8a1ce11422d9e26ab69ec8 5a514.pdf 
SECRETARIA DE ADMINISTRAÇÃO PENITENCIÁRIA, Resolução 558: diretrizes e normativas para o tratamento da população LGBT no Sistema Penitenciário do Estado do Rio de Janeiro. SEAP, 2015.

Disponível em: http://www.silep.planejamento.rj.gov.br/resolucao seap n 558 2905201.htm. Acesso em: 15 maio 2020.

Recebido em: 15/10/2020

Aprovado em: 06/12/2020 